\title{
Edema from Taking Cinnamon for Treatment of Diabetes: Similar Biochemistry and Pathophysiology to Thiazolidinedione Medications
}

\author{
Paul Crawford, MD and Amanda J. Crawford, BA
}

We present a report of cinnamon bark powder $1000 \mathrm{mg}$ daily associated with edema that resolved after stopping the supplement in an adult male. Thiazolidinediones (TZDs) cause fluid retention in those with diabetes or prediabetes. Some medications in this class have been implicated in increased cardiac deaths from this side effect. While medications are effective for diabetes, many people have turned to natural remedies to treat their diabetes instead of conventional pharmaceuticals. Cinnamon is a common agent used, and it has received extensive lay press attention. Chemically, cinnamon bark powder activates peroxisome proliferated activated receptors similar to TZDs. It is reasonable to hypothesize that cinnamon bark powder can cause edema. This case demonstrates that cinnamon bark powder may have a similar side effect profile. Physicians should be aware that consumption of cinnamon bark powder could cause fluid retention and possibly worsen congestive heart failure. (J Am Board Fam Med 2018;31:809-811.)

Keywords: Cinnamon, Edema, Heart Failure, Peroxisome Proliferator-Activated Receptors, Thiazolidinediones

While cinnamon as an herbal remedy has existed for thousands of years, cinnamon as a dietary supplement specifically for lowering glucose has enjoyed increasing popularity in the press. Most lay press articles make a positive connection between cinnamon and prediabetes and type 2 diabetes, but they do caution that studies involving cinnamon for the treatment of prediabetes and type 2 diabetes are few, small, and have had mixed results. This has not stopped patients from supplementing their diets with cinnamon, either in capsule form or by sprinkling cinnamon powder on foods such as oatmeal. Published studies show that cinnamon was one of

This article was externally peer reviewed.

Submitted 20 January 2018; revised 31 May 2018; accepted 5 June 2018.

From the Nellis Family Medicine Residency, Nellis $\mathrm{AFB}, \mathrm{NV}$.

Funding statement: This case resulted from a clinical trial funded by the Air Force Medical Support Agency, the Geneva Foundation, and the 59 Medical Wing Science and Technology office.

Conflict of interest: none declared.

Corresponding author: Paul Crawford, MD, Nellis Family Medicine Residency, 4700 N Las Vegas Blvd, Nellis AFB, NV 89191. the most commonly used herbal products in Palestine, ${ }^{1}$ Australia, ${ }^{2}$ and Austria. ${ }^{3}$

Few studies have examined the adverse effects of cinnamon. Patients experienced dyspepsia when the amount of refined cinnamon ingested was 85 $\mathrm{mg}$ the first month, $250 \mathrm{mg}$ the second month, and $500 \mathrm{mg}$ the third month. ${ }^{4}$ There have also been cases of allergic contact dermatitis/stomatitis from a cinnamal patch test and from cinnamon chewing gum. ${ }^{5,6}$ One case report of an elderly woman reported a diagnosis of cinnamon statin combination-induced hepatitis. ${ }^{7}$ Another case report of an elderly white woman found that 2 weeks of using cinnamon oil pills $500 \mathrm{mg}$ daily exacerbated the patient's rosacea. ${ }^{8}$ It is critical that potential adverse events from cinnamon are reported, and we report a case of peripheral edema from taking cinnamon.

\section{Case Report}

A 57-year-old male with hypertension and type 2 diabetes was enrolled in a clinical trial evaluating the effect of cinnamon bark powder (Cinnamomum cassia) $1000 \mathrm{mg}$ daily versus oral extended release metformin 1000 mg daily versus Cinnulin PF 500 
mg daily on lowering hemoglobin $\mathrm{A} 1 \mathrm{C}$ at least $0.5 \%$ in patients with previously diagnosed type 2 diabetes mellitus. On study enrollment, he had trace lower-extremity edema and a recent normal echocardiogram with normal exercise tolerance. Except for hemoglobin A1C of $6.5 \%$, he had a normal blood count and normal renal and liver function.

He was randomized to take $1000 \mathrm{mg}$ of cinnamon bark powder daily, and within 1 week of starting his study medication, he presented with rapid increase in leg swelling. Investigators stopped his cinnamon bark powder at this time, and his treatment was unblinded. Physical examination revealed no extra heart sounds, jugular venous distension, or hepatojugular reflux, all classic signs of heart failure, but he did have 4+ pitting edema to the knees bilaterally. Renal, liver, and urine tests drawn on that day were normal. Within 5 days of discontinuing cinnamon bark powder, swelling improved to baseline.

Over the next 16 months, the patient developed congestive heart failure with normal ejection fraction, grade 1 diastolic dysfunction and periodic edema.

\section{Discussion}

Five point eight million units of pioglitazone, a thiazolidinedione (TZD), was prescribed in the United States in 2015..$^{9}$ One of the most common side effects of TZDs is peripheral edema. Approximately $5 \%$ of patients using TZDs develop peripheral edema; when TZDs are used with other antidiabetic drugs, the risk of patients developing peripheral edema increases to $18 \% .^{10,11}$

Cinnamon supplements and TZDs have similar molecular mechanisms of action. Peroxisome proliferated activated receptors (PPARs) are ligandactivated nuclear hormone receptors with the isoforms PPAR $\alpha(\alpha)$, PPAR $\gamma(\gamma)$, and PPAR $\delta / \beta(\delta /$ $\beta) .{ }^{12}$ PPAR $\alpha$ is expressed mainly in brown adipose tissue and the liver, while PPAR $\gamma$ is mainly expressed in adipose tissue, and PPAR $/ \beta$ is expressed throughout many tissues. Evidence shows that activation of PPAR $\alpha$ lowers plasma triglycerides and elevates plasma high density lipoprotein cholesterol levels, ${ }^{13}$ and that the activation of PPAR $\gamma$ increases insulin sensitivity and therefore results in antidiabetic effects. ${ }^{14}$

Cinnamon has been shown to upregulate mRNA expression of PPAR $\gamma .{ }^{15}$ Cinnemaldehyde, an active component of cinnamon, was found to induce activation of PPARס, PPAR $\gamma$, and retinoid X receptor (RXR). Cinnamaldehyde may activate PPARy in a different manner than pioglitazone, as cinnamon selectively stimulated PPAR $\gamma$ S342A mutant whereas pioglitazone did not. To gather the biological evidence that cinnamaldehyde increases PPARs transcription, researchers measured the expressions of PPAR $\delta$ and PPAR $\gamma$ target genes in 3T3-L1 adipocytes. The data showed that cinnamaldehyde induced the expression of PPAR $\delta$ and PPAR $\gamma$ target genes, namely aP2 and CD36, in differentiated adipocytes. As a result, PPAR $\delta$, PPAR $y$ and their heterodimeric partner RXR seem to play a part in cinnamaldehyde action in the target tissues, causing an enhancement in insulin sensitivity and fatty acid $\beta$-oxidation and energy uncoupling in skeletal muscle and adipose tissue. ${ }^{16}$ Data also suggest that cinnamon in its water extract form can act as a dual activator of PPAR $\alpha$ and $\gamma$, and may be an alternative to PPAR $\gamma$ activators. ${ }^{17} \mathrm{In}$ mice, the PPAR $\alpha$ mRNA (liver) and PPAR $\gamma$ mRNA (adipose tissue) expression levels were increased significantly in the cinnamon-treated group $(P<.05){ }^{18}$

TZDs also activate PPAR $\gamma$ receptors, and TZD activated PPAR $\gamma$ have been shown to cause edema. In 1 double-blind randomize-controlled 4-way crossover study, pioglitazone and placebo were examined for their effect on renal, systemic, and hormonal responses to changes in sodium intake. Pioglitazone was found to increase diurnal proximal sodium retention in diabetic and hypertensive patients. ${ }^{19}$ One study makes the supposition that because TZDs are PPAR full agonists, a side effect of TZDs is fluid retention with associated peripheral edema due to the alteration of sodium and water reabsorption in the distal collecting ducts of the kidney. ${ }^{20}$ In a meta-analysis assessing the overall risk for developing edema from TZD, there was a 2-fold increase in the risk for developing edema with a TZD compared with placebo, oral antihyperglycemic agents, or insulin. ${ }^{21}$

Coumarin, a chemical precursor to the drug warfarin, is present in cinnamon. In doses above 0.1 $\mathrm{mg} / \mathrm{kg}$, coumarins may cause liver dysfunction (and subsequent fluid retention) in humans. The cinnamon bark powder in this clinical trial was assessed (ExperTox, Deer Spring, TX) to have $0.5 \%$ coumarin, or $5 \mathrm{mg}$ per daily dose. All patients in the 
trial weighed greater than $50 \mathrm{~kg}$; thus coumarin intake was never in the toxic range.

In the current case report, we hypothesize that cinnamon bark powder may have caused edema in this subject through similar mechanisms to TZDs.

The views expressed in this article are those of the authors and do not necessarily represent the official position or policy of the US Government, the Department of Defense, or the Department of the Air Force.

The authors wish to thank Tracy Bogdanovich and Jill Clark for their assistance with this trial.

To see this article online, please go to: http://jabfm.org/content/ 31/5/809.full.

\section{References}

1. Ali-Shtayeh MS, Jamous RM, Jamous RM. Complementary and alternative medicine use amongst Palestinian diabetic patients. Complement Ther Clin Pract 2012;18:16-21.

2. Manya K, Champion B, Dunning T. The use of complementary and alternative medicine among people living with diabetes in Sydney. BMC Complement Altern Med 2012;12:2.

3. Fabian E, Töscher S, Elmadfa I, et al. Use of complementary and alternative medicine supplements in patients with diabetes mellitus. Ann Nutr Metab. 2011;58:101-8.

4. Ranasinghe P, Jayawardena R, Pigera S, et al. Evaluation of pharmacodynamic properties and safety of Cinnamomum zeylanicum (Ceylon cinnamon) in healthy adults: A phase I clinical trial. BMC Complement Altern Med 2017;17:550.

5. Ackermann L, Aalto-Korte K, Jolanki R, et al. Occupational allergic contact dermatitis from cinnamon including one case from airborne exposure. Contact Dermatitis 2009;60:96-9.

6. Kind F, Scherer K, Bircher AJ. Allergic contact stomatitis to cinnamon in chewing gum mistaken as facial angioedema. Allergy 2010;65:276-7.

7. Brancheau D, Patel B, Zughaib M. Do cinnamon supplements cause acute hepatitis? Amer J Case Rep 2015;16:250-4.

8. Campbell TM, Neems R, Moore J. Severe exacerbation of rosacea induced by cinnamon supplements. J Drugs Dermatol 2008;7:586-7.

9. Clincalc. Pioglitazone hydrochloride. Drug Usage Statistics, United States, 2005-2015. Available from: http://clincalc.com/DrugStats/Drugs/PioglitazoneHydrochloride. Accessed May 31, 2018.
10. Horita S, Nakamura M, Satoh N, et al. Thiazolidinediones and edema: Recent advances in the pathogenesis of thiazolidinediones-induced renal sodium retention. PPAR Res 2015;2015:646423.

11. Bełtowski J, Rachańczyk J, Włodarczyk M. Thiazolidinedione-induced fluid retention: Recent insights into the molecular mechanisms. PPAR Res 2013; 2013:628628.

12. Abbas S, Raza ST, Ahmed F, et al. Association of genetic polymorphism of PPAR $\gamma-2$, ACE, MTHFR, FABP-2 and FTO genes in risk prediction of type 2 diabetes mellitus. J Biomed Sci 2013;201320:80.

13. Steiner G, Hamsten A, Hosking J, et al. Effect of fenofibrate on progression of coronary-artery disease in type 2 diabetes: the Diabetes Atherosclerosis Intervention Study, a randomised study. Lancet 2001; 357:905-10.

14. Olefsky JM. Treatment of insulin resistance with peroxisome proliferator-activated receptor gamma agonists. J Clin Invest 2000;106:467-72.

15. Hosni AA, Abdel-Moneim AA, Abdel-Reheim ES, et al. Cinnamaldehyde potentially attenuates gestational hyperglycemia in rats through modulation of PPAR $\gamma$, proinflammatory cytokines and oxidative stress. Biomed Pharmacother 2017;88:52-60.

16. Li JE, Futawaka K, Yamamoto H, et al. Cinnamaldehyde contributes to insulin sensitivity by activating PPARס, PPAR $\gamma$, and RXR. Amer J Chin Med 2015; 43:879-92.

17. Sheng X, Zhang Y, Gong Z, et al. Improved insulin resistance and lipid metabolism by cinnamon extract through activation of peroxisome proliferator-activated receptors. PPAR Res 2008;2008:581348.

18. Kim SH, Choung SY. Antihyperglycemic and antihyperlipidemic action of Cinnamomi cassiae (Cinnamon bark) extract in C57BL/Ks db/db mice. Arch Pharm Res 2010;33:325-33.

19. Zanchi A, Maillard M, Jornayvaz FR, et al. Effects of the peroxisome proliferator-activated receptor (PPAR)-gamma agonist pioglitazone on renal and hormonal responses to salt in diabetic and hypertensive individuals. Diabetologia 2010;53:1568-75.

20. Alemán-González-Duhart D, Tamay-Cach F, Álvarez-Almazán S, et al. Current advances in the biochemical and physiological aspects of the treatment of type 2 diabetes mellitus with thiazolidinediones. PPAR Res 2016;2016:7614270.

21. Berlie HD, Kalus JS, Jaber LA. Thiazolidinediones and the risk of edema: A meta-analysis. Diab Res Clin Prac 2007;76:279-89. 